\title{
Corpos em confecção: consideraçôes sobre os dispositivos científico e midiático em revistas de beleza feminina
}

I 1 Camilla Araújo Lopes Vieira, ${ }^{2}$ Maria Lúcia Magalhães Bosi I

Resumo: Pretende-se problematizar os dispositivos científico e midiático na construção do ideal de corpo magro, mediante a análise de revistas de beleza voltadas ao público feminino. Para tanto, foram selecionadas seções específicas de duas revistas de grande circulação - Boa Forma e Corpo a Corpo -, com vistas a analisar os textos e imagens vinculados ao tema do consumo de alimentos, produtos e serviços, entre outras formas simbólicas que valorizam e garantem longevidade, acesso à boa forma, magreza e beleza, considerados atributos saudáveis. Os resultados evidenciam a profusão de fórmulas ou receitas associando magreza e felicidade, dentre outros ganhos a serem alcançados com disciplina, esforço e, sobretudo, lançando mão do consumo de bens e serviços voltados à estética. Há claro suporte discursivo amparado no saber médico estético especializado diluído na mídia impressa, e protagonizado por especialistas em diferentes domínios disciplinares e profissionais, emprestando legitimidade ou valor de verdade junto aos leitores, na ênfase dos cuidados com a "saúde". Constata-se, assim, uma cumplicidade entre os discursos midiático e biomédico, em um consórcio lucrativo mediante o qual a legitimidade alcançada pelo primeiro se desdobra em um lucrativo mercado para os agentes que detêm o saber (bio)médico-estético.

> Palavras-chave: magreza; biopoder; dispositivo; saúde.

\author{
1 Professora Adjunta do Curso \\ de Psicologia da Universidade \\ Federal do Ceará; doutora em \\ Saúde Coletiva Associação \\ Ampla UFC/UECE/UNIFOR. \\ Endereço eletrônico: tgd. \\ camilla@gmail.com \\ 2 Professora titular da Faculdade \\ de Medicina da Universidade \\ Federal do Ceará; doutora em \\ Saúde Pública pela Fundação \\ Oswaldo Cruz; pós-doutorado \\ no Center for Critical Qualitative \\ Health Research da Universidade \\ de Toronto. Endereço eletrônico: \\ malubosi@ufc.br
}

Recebido em: 05/12/2012 Aprovado em: 14/08/2013 


\section{Introdução}

O que é um corpo? Sem a intenção de oferecer resposta a essa complexa questão, retomando os clássicos para uma historiografia tradicional que certamente atualizaria a dicotomia entre as ciências humanas e sociais e as ciências médicas, partiremos de outro lugar, qual seja: o do corpo como cenário para novos modos de subjetivação, onde relações de poder se estabelecem.

Bourdieu (1990) afirma que diferenças biológicas são formas de justificar diferenças socialmente construídas. Assim, o corpo, aqui tomado em sua perspectiva política, é situado na concretude, enquanto volume materializado, mas sempre resultado de investimentos de poder e de enunciações por parte dos saberes que o montam e o constroem como valor. No estranhamento do protagonista da obra Memórias de minhas putas tristes, temos um bom exemplo:

Nunca pensei na idade como se pensa numa goteira no teto que indica a quantidade de vida que vai nos restando.[...] Comecei a me perguntar quando tomei consciência de ser velho, e acho que foi pouco antes daquele dia. Aos quarenta e dois anos havia acudido ao médico por causa de uma dor nas costas que me estorvava para respirar. Ele não deu importância: é uma dor natural na sua idade, falou. Então - disse eu - o que não é natural é a minha idade. (MARQUES, 2005, p.12-13).

Com Le Breton (2006), entendemos que a condição humana é corporal. O modo como contatamos o mundo e delimitamos os espaços se dá através do corpo. Base identificadora dos traços sociais que nos colocam em posição no mundo, tanto pelo que o corpo comunica pela percepção pelos afetos, quanto pela interpretação dessas manifestações pelos outros. Características definidoras como a aparência, por exemplo, assim como a idade, o sexo, os gestos. Enfim, a vida é assimilada pelo corpo; a vida se realiza no corpo.

Partindo de uma leitura do corpo como superfície na qual se inscrevem "verdades", como campo de domínio e de produção de subjetividades, nosso objetivo é problematizar algumas enunciações veiculadas nas revistas de beleza e estética e refletir sobre as articulações entre os dispositivos científico e midiático na construção do ideal de corpo magro nesses espaços de comunicação e informação.

O conceito de dispositivo é aqui concebido com base na obra de Michel Foucault (1998), englobando uma diversidade de mecanismos. Consoante Agamben (2009), a expressão "dispositivo", tal como formulada por Foucault, pode ser considerada tanto um dito como um não dito, uma rede que implica discursos, instituições, enunciados científicos, proposições morais, com função 
estratégica que gera relações de força. Desse modo, se insere em um jogo de poder, vinculado aos limites do saber. Enraizado ao dispositivo, na sua impregnação mesma, encontra-se um desejo de felicidade. Capturar e subjetivar o desejo constitui a potência específica do dispositivo.

Herdeiro da concepção onde o corpo se impóe como questão a todo modo de pensar, Foucault, em sua ontologia do presente - teoria sobre o sujeito do presente, do hoje, das circunstâncias que o fazem possível - nos ajuda a transmutar a ontologia clássica num deslocamento sobre a questão que é anunciada acerca do corpo. Em lugar da primazia do verbo ser, que sugere uma origem - atribuída a uma biologia - algo a desvelar - atribuído a uma essência - trata-se agora de outra ontologia: a ontologia histórica de nós mesmos, que se interessa pelas condições concretas que nos constituem. Quando denominamos a engrenagem entre saber médico estético, voltada à produção da saúde e da boa forma, e sua veiculação midiática como dispositivos, estamos enfatizando a força discursiva e o caráter de veracidade que os constructos no campo da saúde adquirem, vendáveis através da força das imagens e dos textos que a mídia faz chegar aos leitores. A venda de saúde através da imagem da juventude e da boa forma, propagadas pela imprensa especializada em fitness, cresce aceleradamente e, cada vez mais, se consolida como dispositivo.

Isso posto, demarcamos como questões norteadoras da discussão que aqui se desdobrará: qual referência estética tem sido anunciada pelos dispositivos midiático e médico-estético, tomando como espaço de divulgação e visibilidade duas revistas consagradas junto a uma extenso segmento do público feminino? Por que a magreza tem sido um ideal preconizado e associado à saúde e à beleza? Essas questões nos tomam a partir da complexidade de suas composições.

Para discutir tal complexidade, foram selecionadas para análise as revistas Boa Forma e Corpo a Corpo, meios consolidados na área da beleza e que abordam diversas temáticas em voga no mundo da estética e da saúde corporal. As duas revistas estão no mercado há três décadas, são conhecidas do público geral e acessíveis sobretudo à classe média urbana feminina brasileira. Trazem no editorial forte apelo ao corpo belo, magro, representativo de sucesso. Selecionamos vinhetas, problematizamos os textos e as imagens vinculadas ao tema do consumo de alimentos, produtos e serviços, entre outras formas simbólicas que valorizam e garantem longevidade, acesso à boa forma e magreza, 
considerados atributos saudáveis. Partimos de uma visão crítica baseada nos estudos sobre dispositivos, conjugando análise de conteúdo, na localização das expressōes mais evocativas, analisadas posteriormente consoante a tradição da análise crítica de discurso (ACD).

\section{Corpos em confecção}

Os corpos são produções e, como tal, retratados de formas distintas em diferentes momentos históricos, ou mesmo heterogeneamente no mesmo período. Rodrigues (1975) destaca que cada sociedade elege características que constroem o que o homem deve ser a partir de muitos pontos de vista, inclusive (e, em certos, casos, sobretudo) o físico. São as relaçôes sociais em dado momento histórico que configuram e constroem modelos de ser autorizados socialmente, consoante os valores dos diferentes grupos e sociedades. Ainda segundo o mesmo autor, "reconhecemos no nosso corpo e no das pessoas que conosco se relacionam um dos diversos indicadores da nossa posição social e o manipulamos cuidadosamente em função desse atributo" (p. 45).

Dispositivos atuam como modos de existência, referindo-se ao fazer, aos dizeres e às construçôes sociais. Ancoram-se em leis e normas e também em usos e costumes. As revistas, ao mesmo tempo que reproduzem discursos difundidos pelo saber médico, fabricam, a partir da venda de produtos estéticos e alimentares, modos de ser, de subjetivação. Seus textos pretendem difundir informações sobre como conquistar um corpo mais bonito, mais leve e, por extensão, mais aceito socialmente. Assim sendo, não podemos afirmar uma natureza dos corpos sem considerar que esta leitura já parte da inscrição do homem no campo da cultura e é, pois, carregada de sentidos e verdades. Tal fato se evidencia na inexistência de apenas um referencial de belo possível em certas épocas. Contudo, de acordo com os modelos hegemônicos que se configuram socialmente, no interior da diversidade de padrões observada em cada época, temos modelos de beleza predominantes a serem perseguidos, modelos estes amplamente difundidos, funcionando assim como verdades.

Podemos pensar, tomando como corpus as revistas de beleza e de cuidados corporais femininos direcionadas a um público leitor de classe média, aqui tomadas como material empírico, Corpo a Corpo e Boa Forma, que os corpos ali em destaque são corpos desejados na medida em que legitimados pelos discursos 
que os produzem, pois assim como Foucault (1987, p.28), pensamos que "o corpo

também está diretamente mergulhado num campo político; as relações de poder têm um alcance imediato sobre ele [...], uma tecnologia política do corpo".

Podemos agora conjecturar como certo tipo de corpo - o corpo magro, esguio, com pouca gordura, "chapado", "sequinho", "durinho", "trabalhado", "lapidado", dentre as possibilidades de corporeidades na atualidade - assume preponderância e torna-se modelo de prateleira a ser vendido pelas revistas de beleza voltadas para o público feminino de classe média urbana.

A revista Corpo a Corpo nasceu como um guia, uma espécie de livro com temas bastante abrangentes (CASTRO, 2007). Com tiragem mensal de 135.500 exemplares, seu público-alvo são mulheres das classes $\mathrm{ABC}$ e com faixa etária de 15 a 39 anos (dados consultados no midiakit da revista, http://www.escala. com.br/midiakit/). Nas informaçôes sobre o perfil da revista, temos as seguintes consideraçōes:

Corpo a Corpo é a mais completa revista de beleza do País, pois valoriza a essência de cada mulher. Em suas páginas, a leitora encontrará informaçôes para ter uma silhueta definida e um visual mais bonito e saudável, com dicas de moda, cabelo, maquiagem e cuidados com a pele. Uma revista atual, feita para a mulher que sabe o quanto a aparência é fundamental na vida moderna. (Midiakit, p.2).

Anunciada como a revista top de beleza, traz na capa, a cada mês, uma personalidade em evidência no mundo dos famosos. Nas seçôes principais que estruturam a revista as temáticas são: Mais Bonita; Na Moda; Magra e Saudável; e Corpo em Forma.

Já a revista Boa Forma surgiu nos anos 1980 em formato de guia para profissionais de educação física, reposicionando-se para o público feminino anos depois. Atingindo um público muito semelhante, segue a mesma lógica de cuidados com o corpo e a manutenção da juventude. As matérias que compõem o produto englobam assuntos como beleza, dieta e nutrição, fitness, saúde, além da ênfase à estrela da capa.

Seja nas bancas de revistas ou através de compra por assinaturas, seja nas salas de consultórios médicos ou nos salóes de beleza, tais revistas se espalham e se difundem, disponíveis aos olhares mais curiosos, receitando modelos de saúde e beleza bem-sucedidos.

Na edição de abril de 2010 da revista Corpo a Corpo, algumas chamadas merecem atenção e podem ilustrar nossa reflexão. Percorrendo o que nela consta, indagamos: 
o que implica ou que modos de subjetivação se forjam quando o leitor é lançado a buscar um "cabelo hollywwodiano"? Submetendo-se à "dieta antigordura", o que o sujeito conquista? Ter uma "barriga lisinha", "braços definidos" e "pernas torneadas" permitem que tipo de relação consigo e com o mundo?

Ainda na mesma edição, a capa é ilustrada pela imagem de uma "atriz global", com mais de 40 anos e que, segundo os anúncios, exala vitalidade e sensualidade. Uma matéria exclusiva revela que aos, 42 anos de idade, não é difícil perceber que "os anos foram de uma generosidade ímpar com a beldade. Basta olhar o que se revela." E o que ela diz de tudo isso? "Não sou escrava dos ponteiros da balança. Eu me avalio pela calça jeans. Só me peso quando vou a uma consulta médica e isso faz parte da ficha”. Municiada de profissionais com expertise para assessorar a alimentação, o treino, a pele, o cabelo e tudo que mais possa entrar no rol de saúde e qualidade de vida, a beldade parece advir dos contos de fadas, com a pele branca como a neve, cabelos louros e uma imagem reflexo da Barbie pós-moderna, ideal ocidental da completude e do sucesso.

Percorrendo as chamadas da revista, vimos que a mesma segue anunciando que a modelo de capa do mês revelará seus "mais íntimos segredos de beleza e os exercícios responsáveis pelo corpo enxuto e torneado".O segredo disso tudo? Diz a matéria, uma família linda, um trabalho que ela adora, um pouco de tempo para cultivar sua individualidade e, claro, dieta saudável e exercícios físicos feitos com regularidade e disciplina. Isso sem contar alguns segredinhos para manter o visual e a saúde no lugar. Afinal de contas, com a correria desgastante do dia a dia (ela grava seis dias por semana), não custa dar uma mãozinha à natureza (LENZ; IPPOLITO, 2010). Cuidar do corpo implica cuidar de si a tal ponto e de tal modo que estamos diante do que Costa (2004) denomina personalidade somática: somos o nosso corpo e o que ele revela de nós. $\mathrm{O}$ autor não defende que estamos diante de perda dos valores na sociedade atual, pois essa ideia, para ele, é falsa. O que há hoje é outra forma de apresentação dos valores, tendo como pilares a mitologia científica e a moda.

Corpo a Corpo edição de dezembro de 2011 apresenta uma jovem atriz segurando os seios, com um colar e uma calcinha dourados, ressaltando o brilho das festas de fim de ano. A maquiagem é forte e a postura da atriz alude à sensualidade de seu corpo, quase nu. Lembra-nos Foucault (1979, p.147), quando falava de poder e corpo e dizia sobre a vertente de poder que investe 
não mais na repressão como forma de controle, mas na estimulação: "Fique nu... mas seja magro, bonito, bronzeado!”. Trata-se de uma exploração econômica do corpo pela via da saúde, do mundo da malhação, da confecção do corpo. A revista revela corpos esculturais e sua determinação pelo personagem leva a buscar melhoras constantes. A matéria ressalta seu peso, altura, as medidas de seu corpo, os exercícios que pratica, os recursos estéticos, seu cardápio, a marca das maquiagens que leva à mão para "se cuidar", além de produtos que ela enumera e que estão presentes do banho à mala de viagens. Tudo disponível para que a leitura se torne igual, que se identifique com a imagem e lute com disciplina, para também "chegar lá."

Em Boa Forma, edição de abril de 2012, a mesma atriz que fez a capa da revista citada acima é destaque por outra editora. A matéria ressalta: "a revelação da Globo entrega os truques destas curvas". Mais uma vez, a imagem mostra suas curvas sensuais, e a matéria informa que são resultado de "hábitos saudáveis e escolhas inteligentes que contribuem para ela não precisar brigar com a balança." Novamente, suas medidas vêm em destaque, sua dieta, uma receita de sopa que ela mesma faz e que, portanto, a leitora pode aprender e fazer. Dicas de como se manter bela, jovem, saudável e ativa recheiam a matéria, quase nada diferente da anterior, não fossem as fotos e os novos produtos de consumo para a beleza e a saúde.

A edição de julho de 2011 de Boa Forma traz uma apresentadora e ex-modelo, magra, alta, loira e bem-sucedida. Fotos da matéria ocupam páginas inteiras e o anúncio diz que "ela pode tudo". Tem agenda lotada de compromissos, entre eles malhar, comer direito e cuidar da beleza. À leitora cabe descobrir os truques e segredos, seguir à risca, manter a mesma disciplina e o controle. Novamente o cardápio da beldade, seus segredos de beleza e seus mandamentos para o corpo perfeito aparecem como que mantras, rezas, alusivos ao esforço, à constância e à determinação. Nas palavras de sua personal trainer, "o esforço que ela faz para conquistar o que quer, ela sua a camisa e fecha a boca para manter a forma. Se passa vontade de comer uma porção de coisas, é porque estabeleceu metas e sabe que, ao alcançá-las, o prazer será muito maior” (Boa Forma, jul 2011, p.25).

A busca de adequação e ajustamento do corpo aos padrões impostos socialmente por práticas discursivas hegemônicas é uma forma de controle corporal. Propagar corpos enxutos, sarados, chapados, poderosos, durinhos, saudáveis e jovens é anunciar uma exaustiva lapidação da magreza - em sua tensão com a gordura, 
portanto - com fortes implicações para a produção de subjetividades, tendo em vista que são exatamente as construções de saber e poder que as engendram.

Diante da invasão das imagens nas matérias, algumas ocupando páginas inteiras de um corpo bem trabalhado com máquinas de academias e muita dieta restritiva, reconhecemos que naquilo que se anuncia quase sempre se vela o não dito e sua força discursiva. Ao lado de uma suposta generosidade da natureza que revela uma beleza sem pretensões ou muitos esforços, oculta-se um exaustivo trabalho de cuidados corporais, alimentares e estéticos, de rituais diários e gestão do corpo que abarcam muito mais que um simples exercício ou qualquer tipo de alimento: é o estilo de vida. O prazer está no sacrifício, na privação. A ascese corporal revela-se nas sucessivas recusas ao prazer gustativo de alimentos gordurosos ou saborosos; na malhação diária que trabalha cada parte do corpo esquadrinhada e isolada do todo.

A ciência e a tecnologia estão a serviço da busca pela perfeição corporal. Como aliado, o saber científico corrobora os valores que alimentam o padrão de beleza vinculado à magreza e à disciplina, legitimando o esforço ininterrupto. Assim é que, nos diferentes contextos em que atuam, as técnicas disciplinares revelam e expulsam a incômoda diferença, ratificando sempre a adequação às normas, aos ditames, tomando o corpo como registro de poder associado a um modelo hegemônico de beleza.

Foucault (1997, p.12) assevera que as práticas discursivas não são meros modos de fabricação dos discursos, mas "ganham corpo em conjuntos técnicos, instituições, em esquemas de comportamento, em tipos de transmissão e difusão, em formas pedagógicas, que ao mesmo tempo as impõem e as mantêm”. As linhas de exercícios de saber-poder se articulam tanto entre o que se diz quanto com o que se vê. É preciso considerar que não comportam uma forma comum, uma correspondência biunívoca. O saber vai do enunciável ao visível e do visível ao enunciável, mas em tensão, através de relações de forças. Há um encontro forçado onde se intercalam o que os olhos veem e o que se pronuncia.

As afirmações de Foucault a que acabamos de aludir nos parecem úteis na análise em curso: de uma aparente naturalização da beleza conquistada quase sem esforços, vemos se desdobrar um forte e incessante trabalho corporal. $\mathrm{O}$ corpo natural de hoje é, sobretudo, aquele que não cessa de incitar disciplina, controle, prática de exercícios, cirurgias, uso de tecnologias corporais, nutricionais 
e outras. Assim, é entre os modos de viver a saúde, de produção de uma estética

da identificação - diferente da estética da existência para os gregos - pela via do consumo, que os corpos magros como ideal a ser seguido se justificam.

Os cuidados com o corpo e o discurso da saúde em nome da qualidade de vida são propagados e alardeados pela mídia, aqui a impressa, especialmente dos magazines para cuidados com a beleza, como campo de enunciação dos cuidados com o corpo. Quando destacamos o corpo magro, não estamos aqui nos referindo aos sujeitos esqueléticos que se recusam obstinadamente a comer, denominados anoréxicos pelo discurso médico. Também não estamos negando sua existência e nem tampouco olvidando a vinculação desses transtornos com o fenômeno aqui analisado, conforme importantes estudos de Bosi et al. (2006) e Uchimura (2008). O corpo magro aqui referido é o corpo trabalhado, que malha, que come alimentos ditos naturais, funcionais, com baixo percentual de gordura, é um "corpo light/ diet” e que, por isso, serve às mais diversas disciplinas médico-estéticas.

$\mathrm{O}$ culto ao corpo na atualidade não é uma referência à natureza do corpo, ainda que as publicações aqui tomadas para análise queiram ressaltar o estado de beleza "natural". Segundo Andrieu (2008), é a égide do domínio de si, portanto dinâmico e manipulável pela ciência. Ele é refém de qualquer nova descoberta, objeto de novos investimentos, para onde a tecnologia fitness e a estética se voltam e vendem seus produtos e serviços. A superfície lisa da pele e o volume muscular impõem-se como leis absolutas no trabalho das aparências, engendradas pela tecnociência.

$\mathrm{Na}$ reinvenção contextualizada do corpo como forma de expressão, segundo Lucas e Hoff (2007, p.101), “a dietética volta a encontrar seu espaço. Não mais como uma estética da existência, mas como um processo identitário”. Isso porque na dietética grega, tal como examinada por Foucault (1988), o fundamento se encontra em uma permanente busca da justa medida, que é, antes de tudo, uma arte de viver. Assim, o exercício constante visava a uma condução de vida em equilíbrio, adequada. Mais que modos de se alimentar, a dietética refere-se à amplitude das preocupações do homem grego com uma vida cada vez mais harmônica.

Hoje, na associação entre mídia e ciência, a estética da existência cede espaço para a assimilação em série dos ditames, não raro falseados pelas propagandas de juventude eterna, sendo o consumo o vetor mais importante para a construção de uma saúde perfeita. Para Luz, Sabino e Mattos (2013), os meios de comunicação, especialmente a imprensa escrita, propagam para a sociedade modos de pensar e 
agir. Diríamos que propagam modos de ser, alimentam estilísticas da existência, produzindo modos de subjetivação que são baseados em verdades derivadas do campo amplo da ciência médica. Ainda segundo os autores, os saberes gerados pela ciência contemporânea têm o traço comum de intervir e modificar as coisas. Certamente, o corpo não fica de fora. Os autores utilizam a expressão que aqui cabe muito bem, a mitologização da ciência, para explicitar o caráter de influência intelectual e moral desse campo de saber no imaginário cotidiano

Kehl $(2002)^{1}$ considera que o corpo hoje é, ao mesmo tempo, objeto de investimento do eu e imagem oferecida aos outros. Tornado o mais fiel objeto de verdade dos sujeitos, o corpo tem sido submetido indefinidamente à rigorosa disciplina da forma que, estrategicamente, tem sido superposta a outra indústria, a da saúde. A um só tempo o corpo é escravo, submetido sumariamente à incessante disciplina, e senhor, pois é a mais absoluta fonte de sacrifício de tempo, dos prazeres, e via de investimentos afetivos, e para boa parte das leitoras, das parcas economias. Assim, os diversos discursos, seja o filosófico, o religioso, o moral, estão todos solapados pela defesa da (pretensa) saúde com a variadíssima indústria do corpo.

O corpo é visto cada vez mais como instrumento para atingir modelos identitários que nada diferem de imposiçôes sociais difundidas pelos mais diversos meios de convencimento: da educação à mídia. Os modelos de identidade são cada vez mais difíceis de atingir e exigem também altas quantias, além de incomensurável esforço físico-corporal e tempo (MISKOLCI, 2006, p. 682). Trata-se da produção de dois campos: por um lado, os corpos produzidos em série, corpos padronizados e, por outro, subjetividades controladas e manipuladas. A formação das subjetividades incorpora, então, valores dominantes que acabam por aderir aos meios - meios estes liderados pelo discurso da ciência ou em nome da ciência e tendo a mídia como o mais forte assessor - que anunciam a integração a um grupo socialmente mais aceito, levando as pessoas a crerem que estão mais felizes, mais belas, mais realizadas.

O corpo esguio e desejado da atriz, com pouca gordura, tonificada - e de tantas outras celebridades que mês a mês cobrem as capas de importantes revistas de cuidados corporais e beleza feminina - revela uma configuração sutil e engenhosa do poder, pois trata-se de um corpo exaustivamente trabalhado, disciplinado, 
cuidado; trata-se também das repercussões do poder em sua positividade - afinal, como afirmou Foucault, se o poder fosse só opressor, não atrairia tanto interesse.

Essa faceta "positiva" do poder ora assinalada nos ajuda a entender o que, à primeira vista, gera estranhamento: o que faz com que as pessoas, diante de tantos sacrifícios, de tantas privações, continuem desejosas de se manter na linha, sujeitando-se ao que a ciência e a mídia engendram? Precisamente, é o que Foucault nomeia como positividade do poder. A sujeição dos corpos ao exercício diário, literalmente, não se faz sob coerção explícita de alguém ou alguma força localizável que o obriga a isso. Quer dizer que pode haver um "saber" do corpo que não é exatamente a ciência de seu funcionamento, e um controle de suas forças que é mais que a capacidade de vencê-las; esse saber e esse controle constituem o que se poderia chamar "a tecnologia política do corpo" (FOUCAULT, 1987, p.28).

Foucault (1988) nos resgata a construção de um poder, outrora soberano, que se estruturou sobre o direito de vida e morte. Trata-se do direito de causar a morte ou de deixar viver. Ocorre uma transformação importante dos referenciais e esquemas norteadores dos mecanismos de poder no Ocidente a partir da época clássica. O poder agora é muito mais destinado a fazer crescer as forças e ordenálas no sentido de fazer viver, de colocar na vida toda a potência de investimento e sobre ela tudo deve funcionar.

O corpo é uma realidade biopolítica e a medicina, estratégia biopolítica. Essas são as colocações de Foucault (1979), fundamentais para nossas investigaçôes sobre o corpo e ideais de beleza na contemporaneidade, tendo a biomedicina como suporte na legitimação do que a mídia veicula. O que significa dizer isso? O corpo como realidade biopolítica e a medicina como estratégia?

Nas considerações sobre o capitalismo, o autor discorda do discurso vigente que apontaria um franco processo de privatização da medicina. Na verdade, ele vai nos mostrar que o processo foi inverso. A hipótese é que, com o capitalismo, não se deu a passagem de uma medicina coletiva para uma medicina privada, mas justamente o contrário; que o capitalismo, desenvolvendo-se em fins do século XVIII e início do século XIX, socializou um primeiro objeto que foi o corpo enquanto força de produção, força de trabalho. (FOUCAULT, 1979, p.80).

$\mathrm{O}$ que Foucault pretendia era mostrar que o capitalismo não produziu uma ação de individualização do exercício da medicina, mas ao contrário, lançou sua 
dominação - seu saber e seu poder - sobre o coletivo, o social. Assim, o controle da sociedade passou a ser operado no e com o corpo. Então, o que significa tomar o corpo como realidade biopolítica? Certamente, o campo do domínio, do poder que se exerce sobre o corpo e a partir dele. Não se trata de um poder localizável ou que tenha uma natureza. Essa certamente foi uma brilhante construção trazida por Foucault, ainda que não tenha pretendido abordar diretamente tal temática. Tal como já aqui aludido, quando falamos de poder, é falso defini-lo tão somente "como algo que diz não, que impõe limites, que castiga" (MACHADO, 1998, p.XV). O poder tem também um aspecto positivo, produtivo, transformador.

É esse aspecto positivo, de certa forma, revolucionário enquanto concepção, que pode elucidar o fato de o corpo humano se tornar objeto, essencialmente para melhorá-lo, adestrá-lo, capacitá-lo. Ora, esse ponto é fundamental, haja vista o corpo magro, para manter-se como tal, ter que ser constantemente trabalhado, aprimorado.

A fabricação de corpos construídos como esguios, versáteis, móveis, livres e libertos passa pela fabricação também de um modelo de si, de relação consigo e com os outros. Operar o corpo - muitas vezes literalmente - através da malhação e de demais práticas de exercícios e esportes; do consumo de alimentos naturais, light, diet, enriquecidos nutricionalmente; do consumo também de diversos serviços e tratamentos para a pele, os cabelos, dentre outros cuidados. Cuidar do corpo passa pela construção de modos de subjetivação específicos de uma, também específica, época.

O corpo de hoje é descoberto e cartografado, radicalmente. Foucault (1980) diz que o corpo é um espaço em que as marcas - em suas linhas, superfícies - são fixadas pelo atlas anatômico. E esse é o campo de domínio do saber médico. Nas reflexôes de Soares (2008, p.72), se esse atlas se presta a fornecer elementos para o domínio através das pedagogias do corpo e das aparências, os segredos saem de cena para a revelação das aparências.

Não é mais o que está escondido debaixo da pele, mas sim o que se pode fazer com as superfícies. O peso, os excessos e as faltas, as desarmonias. [...] Esta estética anuncia uma ciência da aparência, ela convida a experiência de criação a modificar o 'aceito' em proveito do 'desejado' transformando as aparências por si só em fronteiras de possibilidade técnica.

Assim, é o que se apresenta, e não o que se representa, que está evidente. É o embelezamento - argumentado como reflexo de vigor e juventude - que adensa as 
práticas de cuidados, numa confecção cotidiana do corpo. O domínio, a consciência

de seu próprio corpo só puderam ser adquiridos pelos efeitos do investimento do corpo pelo poder: a ginástica, os exercícios, o desenvolvimento muscular, a nudez, a exaltação do corpo belo...tudo isso conduz ao desejo do seu próprio corpo através de um trabalho insistente, meticuloso(FOUCAULT, 1998, p. 147).

Como podemos pensar a captura dos corpos hoje? Qual o lugar das descobertas tecno-científicas? Como podemos pensar qual via agora, predominantemente, segue controlando os corpos, ou melhor, que tipo de controle se exerce hoje? Quando vemos tantas pessoas procurando atividades físicas associadas a uma boa alimentação para melhorar o corpo em nome da saúde, para emagrecer; quando vemos a multidão de pessoas que viram adeptos, por exemplo, das corridas de rua, dos esportes coletivos; quando percebemos o valor crescente atribuído a um tipo de imagem que transmite mais que higiene, sucesso, alegria, leveza, flexibilidade, maleabilidade, juventude, estamos diante de quê? Como podemos compreender tais fenômenos para além deles? Além de ver, de constatar tais fatos, o que dizer desse estado de coisas? Para desvelá-los, há que se considerar a dimensão do poder.

$\mathrm{O}$ poder, não como aquilo que alguém possui ou que emana de alguém. $\mathrm{Na}$ verdade, o poder é possível porque há dispersōes, intermediações, redes, apoios recíprocos, sendo as disposições de poder, mais que as regularidades institucionais, o que interessa. $\mathrm{O}$ que há de fundamental no poder é que ele se exerce sempre sobre o corpo. Há, na verdade, entre o corpo e o poder político, uma relação direta. A construção do indivíduo é dada pelos efeitos do poder, pois este é procedimento para a individuação. Deslocado para o poder que gere vida, se exerce positivamente, possibilitando os coletivos, as populações não mais norteadas por uma estratégia jurídica, mas biológica. O poder se exerce e se situa, na verdade se funda "ao nível da vida, da espécie, da raça e dos fenômenos maciços de população” (FOUCAULT, 1998, p.129).

Os procedimentos de poder - e podemos incluir aqui as diversas tecnologias da vida, desde os procedimentos de rejuvenescimento até a preservação dos cordóes umbilicais para produção de células-tronco, os adietamentos em nome da juventude - não cessam de se esquivar da morte. Os pontos de ancoragem do poder se estruturam sobre a vida, ao longo dela, em seu desenrolar. A morte é uma equação que sempre faz sobrar um resto, mas que, a todo momento, produz novos modos de agenciamento, de controle e de poder. 
Desde o século XVII, existem duas formas integradas de poder sobre a vida: o adestramento dos corpos, ampliando suas capacidades, potencializando suas forças, tornando-os útil, dóceis. Seria o que Foucault denominou de anátomopolítica do corpo humano, integrando sistemas de controle eficazes e econômicos; e centrado no corpo como suporte de processos biológicos, com controles reguladores e intervenções no nível da saúde de uma população, nascimento, mortalidade, duração da vida, etc. Trata-se da biopolitica da população. Fica claro aqui que a função já não é mais matar, mas investir na vida, numa gestão calculista. Abre-se a era do biopoder. Paiva (2000, p.118) ressalta que "como já se percebe, esse poder sobre a vida encontrará no corpo e na sexualidade objetos e instrumentos privilegiados no seu exercício".

Como vimos, diante de nosso interesse em trabalhar com revistas que acenam, pela via do consumo de alimentos e produtos, para um corpo belo e magro, tal construção é estruturada na articulação entre os dispositivos médico/científico/ estético e o midiático, produtores de realidades na medida em que se dá no conjunto de práticas sociais construídas historicamente, exercendo-se no plano das disciplinas com seus efeitos de normalização.

Nas revistas se constroem modelos estéticos para uma vida feliz pela via dos cuidados corporais, produzindo impactos e efeitos sobre o que seria certo modo de ser mulher, pautado em valores que conciliam os domínios discursivos do que é ser mulher hoje. Fica evidente a estreita relação entre a construção da feminilidade com a disciplina alimentar, o investimento estético na imagem de si como ressaltando vitalidade, juventude e esbeltez. Diferentemente de outras épocas, o mundo feminino atual não parece ter nada a revelar, pois está no que se mostra, literalmente.

Bauman (2011, p.159) considera que, na sociedade atual, o exercício da boa forma guarda sempre um gosto amargo, tendo em vista que para a busca de um corpo esculpido, revelado em seus mais detalhados músculos expostos ao olhar alheio, não cessa de se inscrever um tormento de ansiedade do corpo fora de forma. Daí que "nenhuma quantidade de cuidado ou treino do corpo, em qualquer momento, é capaz de pôr fim à tormentosa suspeita do mau funcionamento". Objeto de culto narcisista, o corpo, para Baudrillard (2010, p.174), vincula-se à beleza e ao erotismo como dois motivos condutores de muita importância. O modelo de corpo feminino, segundo o pesquisador da 
pós-modernidade, é prioritário e dirige o que chama de nova ética. "A beleza tornou-se para a mulher imperativo absoluto religioso", pois trata-se de um atributo moral, signo de eleição e salvação.

Como o modelo de uma máquina funcionando, sua engrenagem, em que uma parte não se movimenta isoladamente, também tem sido a parceria entre mídia/ saberes especializados de medicina estética/produtos tecnológicos. Podemos pensar em uma indústria da beleza que articula modelos ideais de beleza, juventude e saúde, uma mídia no entorno de saberes peritos - saber científico-estéticonutricional, por exemplo autorizando discursos dominantes, na prescrição ideal.

A sociedade atual possibilita, portanto, novas formas de ser e de cultuar o corpo e a aparência. Novos elementos contribuem para a transformação, tais como o crescimento do papel da mídia, que reforçou a participação do corpo físico na construção da subjetividade de dois modos, segundo Costa (2004, p.166): "primeiro pela propaganda comercial de cosméticos, fármacos e instrumentos de aperfeiçoamento da forma corporal; segundo, pela identificação de certos predicados corporais ao sucesso social”. Estamos, hoje, diante da conformação de uma feminilidade hegemônica, socialmente compartilhada como referência do belo, ainda que nem todos o tomem como possibilidade, tendo em vista que a via do consumo custa caro e requer muita disciplina.

Ter um corpo como o dos astros de TV e estrelas da moda expostos nas revistas é mais que simplesmente atingir um bem-estar. Significa fazer parte de um grupo social, identificar-se com modos de existência onde a aparência é o sujeito; ter essa necessidade exige os meios de satisfazê-la. Nesse sentido, ter um corpo com baixo percentual de gordura e definido, torneado, através de uma "alimentação saudável", consumo de produtos de última geração e manter-se disciplinado na prática de atividades físicas regulares é o caminho para o portal mágico da felicidade. Mediante o consumo - a um custo elevadíssimo - de um arsenal de produtos e tecnologias disponíveis no mercado e inacessíveis à maioria da população brasileira.

A relação do sujeito com o corpo, portanto, é construção histórica e implementa um jogo de verdade do sujeito em relação ao seu corpo que consiste em estar sempre em busca de um outro corpo, implicando um trabalho exaustivo de cuidados e práticas de melhoramento norteados por saberes "verdadeiros", saberes peritos, a última palavra acerca do que é melhor para o corpo conquistar os tão sonhados objetivos. Mais que isto: implica consumo. 
Importante território de enunciação, "a comunicação midiática [...] já deixa entrever, na enunciação das transformações das técnicas de si, aquilo que constitui o alvo das estratégias de poder na sociedade contemporânea" segundo Lucas e Hoff (2007, p. 93). A magreza saudável, o corpo bem cuidado através de atividades físicas e reeducação alimentar, tem sido um mote de significativo valor simbólico para as coletividades, especialmente as que têm acesso aos serviços e podem consumir produtos feitos para esse fim. Assim, nas políticas públicas de saúde voltadas para o cuidado de si, cuidado dos corpos e das vidas particularizáveis, vemos - incitando a ideia de liberdade, de autonomia - mas apenas numa escolha elencada pelo próprio discurso oficial de saúde, dentro do que é aceito, possível revelando seu controle. A medicina se fortalece como método de controle social, tendo em vista que vigia, controla e distribui os indivíduos como objeto de seu saber. Basta pensarmos aqui na intolerância aos fumantes como um grupo que outrora ocupava outro lugar social.

Numa crítica à medicina em sua "essência", podemos construir, dialogando com Foucault, que o saber médico é negativo por si mesmo, sobretudo quando acerta, porque sua mecânica destrutiva - ver a doença como algo a combater - cria as condições de novas enfermidades, que serão mais difíceis de controlar. Onocko (2006) ressalta que não existe vida sem intercorrências e essa consideração nos é relevante por sugerir a impossível busca pelo corpo ideal, pela saúde perfeita, sem incômodo, sem mal-estar, que eternamente reflita juventude e vitalidade. Viver com intercorrências, diz a autora, é experimentar uma vida de surpresas, inesperados, é padecer, é sempre se manter na busca pelo desejo de ser feliz. Na medida em que a publicidade descobriu isso, os investimentos serão sempre infinitos.

Tempo acumulado ou um tempo juventude que se persegue? Há uma frenética corrida contra o tempo em nossos dias e Foucault (1997, p.130) já nos advertia que a grande preocupação que se tem em esquivar da morte se deve muito menos a um novo fantasma, uma nova angústia "que, por acaso, a torne insuportável para as nossas sociedades, do que ao fato que os procedimentos do poder não cansarem de se afastar dela".

\section{Para concluir}

Consideramos que as palavras, textos e imagens sobre o corpo, beleza e saúde constituem discurso validado socialmente, tomado como referência por um 
importante número de pessoas e compondo uma intricada rede de relações que imbricam história e tecnologia num domínio específico que produz poder. Sendo assim, as revistas que tomamos como objeto são importantes fontes de evidência do corpo magro como referência.

O discurso científico, que aparece nas páginas das revistas através da fala dos especialistas, sejam médicos, nutricionistas, educadores físicos e outros tantos profissionais de saúde, funciona consoante um padrão de enunciação, com regras preestabelecidas de como atingir o proposto exercendo poder e controle sobre os corpos. O discurso midiático dilui o vocabulário científico, tornando-o acessível e "palatável" para o consumo dos leitores externos ao campo científico. Resultam matérias que legitimam um corpo confeccionado por especialistas, numa espécie de julgamento do que é considerado certo ou errado, pela ciência, em nome da saúde.

Revela-se assim, nas revistas analisadas, um claro suporte discursivo amparado no saber médico-estético especializado, tendo como porta-vozes especialistas em diferentes domínios disciplinares e profissionais, emprestando legitimidade ou valor de verdade junto aos leitores, sob o pretexto de cuidados com a "saúde". Mais que isto: constata-se uma cumplicidade entre os discursos midiático e biomédico, em um consórcio lucrativo para ambos os segmentos, mediante o qual a legitimidade alcançada pelo primeiro se desdobra em um lucrativo mercado para os agentes que detêm o saber (bio)médico-estético. ${ }^{2}$

\section{Referências}

ANDRIEU, B. Corps: cultes du corps. Encyclopedia Universalis, 2008. Disponível em http:// www.universalis.fr Acesso em: 02 maio 2013.

AGAMBEM, G. O que é o contemporâneo? E outros ensaios. Chapecó: Argos-Unochapecó, 2009.p.28.

BAUDRILLARD, J. A sociedade de consumo. Lisboa: Arte e comunicação, 2010.

BAUMAN, Z. Vida em fragmentos: sobre ética pós-moderna. Rio de Janeiro: Zahar, 2011. BOSI, M.L.M. et al. Autopercepção da imagem corporal entre estudantes de nutrição: um estudo no município do Rio de Janeiro. Jornal brasileiro de psiquiatria [online], v.55, n.2, p.108-113, 2006.

. Comportamento alimentar e imagem corporal entre estudantes de educação física. Jornal brasileiro de psiquiatria [online], v.57, n.1, p. 28-33, 2008. 
BOA FORMA. São Paulo, Abril, n. 266, 01 abr. 2009. Mensal. Disponível em: <www. boaforma.abril.com.br>. Acesso em: 01 abr. 2009.

BOURDIEU, P. O poder simbólico. Rio de Janeiro: Bertrand Brasil, 1990.

COSTA, J.F. O vestígio e a aura. Rio de Janeiro: Garamond, 2004.

FOUCAULT, M. Vigiar e punir. Petrópolis: Vozes, 1979. . Resumo dos cursos do Collège de France (1970-1982). Rio de Janeiro, 1997. _. Vigiar e punir: nascimento da prisão. Petrópolis: Vozes, 1987. - Microfísica do poder. Rio de Janeiro: Graal, 1980. _. O nascimento da clínica. Rio de Janeiro: Forense Universitária, 1980.

LE BRETON, D. A sociologia do corpo. Petrópolis: Vozes, 2006.

LUCAS, L.; HOFF, T. Da cronobiologia aos neurocosméticos: o advento do corpo-mídia no discurso publicitário da beleza. In: DAVI, A.S.L.; ARAUJO, D.C.; BRUNO, F. (Orgs.). Imagem, visibilidade e cultura midiática. Porto Alegre: Sulina, 2007.

LUZ, M.T.; SABINO, C.; MATTOS, R.S. A ciência como cultura do mundo contemporâneo: a utopia dos saberes das (bio) ciências e a construção midiática do imaginário social. Sociologias, Porto Alegre, v. 15, n.32, abr. 2013.

MACHADO, R. Por uma genealogia do poder. In: FOUCAULT, M. Microfísica do poder. Rio de Janeiro: Graal, 1998, p. XV.

MARQUES, G.G. Memórias de minhas putas tristes. Rio de Janeiro: Record, 2005.

MISKOLCHI, R. Corpos elétricos: do assujeitamento à estética da existência. Revista Estudos Feministas, Florianópolis, v.14, n.3, p.681-193, set-dez 2006.

ONOCKO, R.C. A promoção à saúde e a clínica: o dilema "promocionista”. In: CASTRO, A.; MALO, M. (Org.). SUS ressignificando a promoção da saúde. São Paulo: Hucitec, 2006. PAIVA. C. S. Sujeito e laço social: a produção de subjetividade na arqueologia de Michael Foucault. Rio de Janeiro: Relume-Dumará, 2000.

RODRIGUES, J. C. Tabu do corpo. Rio de Janeiro: Achiamé, 1975.

SOARES, C.L. A educação do corpo e o trabalho das aparências: o predomínio do olhar. In: ALBUQUERQUE J., VEIGA NETO, A. SOUSA FILHO, A. (Orgs.). Belo Horizonte: Autêntica, 2008 (Coleção Estudos Foucaultianos).

\section{Notas}

${ }^{1}$ Colunista e psicanalista, em comentário da matéria veiculada no dia 30 de junho de 2012 no jornal Folha de São Paulo.

${ }^{2}$ C.A.L. Vieira e M.L.M. Bosi participaram da concepção, análise e interpretação dos dados, redação do artigo e aprovação final da versão a ser publicada. 
Making bodies: considerations on scientific and media devices in women's beauty magazines

This paper aims to confront scientific and media devices in the construction of the ideal thin body, through the analysis of womens's beauty magazines. We selected two specific sections of large circulation magazines - Boa Forma and Corpo a Corpo - with a view to analyzing texts and images related to the issue of food consumption, products and services, among other symbolic forms that ensure and value life expectancy, access to fitness, thinness and beauty, considered healthy attributes. The results show the profusion of formulas or recipes associating thinness and happiness, among other gains to be achieved with discipline, effort and, above all, making use of the consumption of goods and services for the aesthetics. There is clear discursive support based on medical-aesthetic specialized knowledge diluted in the print media, and played by specialists in different disciplines and professional fields, lending legitimacy or truth value to readers, emphasizing "health care". It seems that there is complicity between the media and biomedical discourses in a lucrative consortium whereby the legitimacy achieved by the former unfolds into a lucrative market for agents that hold (bio) medical-aesthetic knowledge.

Key words: thinness; biopower; device; health. 